\title{
Synthesis, X-ray Structure and Evaluation of Bactericidal Activity of an o-vanillin Functionalized Schiff Base
}

\author{
Prafullya Kumar Mudi ${ }^{1}$, Smriti Pradhan ${ }^{2}$, Amrita Sahu ${ }^{3}$, Dipanwita Saha ${ }^{2}$, Bhaskar Biswas ${ }^{1, *}$ (i) \\ ${ }^{1}$ Department of Chemistry, University of North Bengal, Darjeeling 734013, India \\ ${ }^{2}$ Department of Biotechnology, University of North Bengal, Darjeeling 734013, India \\ ${ }^{3}$ Department of Electrical Engineering, Temple University, Philadelphia 741235, USA \\ E-mail: bhaskarbiswas@nbu.ac.in, icbbiswas@gmail.com
}

Received: 17 November 2020; Revised: 16 December 2020; Accepted: 21 December 2020

\begin{abstract}
The present study reports the synthesis, crystal structure and evaluation of biological activities of a Schiff base, [L = (Z)-2-methoxy-6-(((2-methoxyphenyl) imino) methyl) phenol]. X-ray structure of Schiff base reveals that the compound crystallizes in the orthorhombic system with Pca space group. The Schiff base adopts two methoxy groups, one phenolic-OH and one azomethine group and exists in a $Z$-stereomer. Investigation on the self-assembled structure of the Schiff base exhibits the formation of a 3D supramolecular architecture through intermolecular $\mathrm{O} \cdots \mathrm{H}$ hydrogen bonding interactions. The bactericidal activity of the Schiff base has been examined against some pathogenic bacteria.
\end{abstract}

Keywords: Schiff base, X-ray structure, supramolecular architecture, bactericidal activity

\section{Introduction}

Schiff bases are an important class of molecules for their easy preparative accessibility, structural versatility and diverse applications in modern sciences [1-7]. They exhibit interesting coordinative capability towards metal ions and the metal-Schiff base compounds/chelates have been considered as important compounds for the development of magnetic materials, highly efficient catalysts, bio-inspired oxidation processes, smart photoluminescent materials, therapeutic agents and so on [8-12]. Schiff bases containing different hetero atoms as donor centres like N, O, S, P have emerged as a promising field of research in coordination chemistry since the metal-Schiff base compounds may tune the morphological, physiological, and pharmacological properties to some great extent [13-15]. Furthermore, among the various aromatic aldehydes, vanillin or 3-methoxybenzaldehyde is a constituent of fruits and obtained from the plant Vanilla Planifolia. Moreover, o-vanillin (aromatic hydroxyaldehydes) functionalized Schiff bases show high stability in the ligand backbone and facilitate the formation of metal complex of varied functionalities [16-18]. The chelating behaviour of o-vanilin functionalized Schiff bases is found good and well documented in scientific literatures [19, 20]. The vanillin functionalized Schiff bases also exhibit good bactericidal as well as biological activity [20]. Recently, we synthesized a dicopper (II) complex employing this Schiff base which showed good bio-mimetic oxidation with high efficiency [20]. With an aim to study the structural and antibacterial effect of the Schiff base, herein, a vanillin functionalized Schiff base has been synthesized and crystallographically characterized. The bactericidal properties of the synthetic Schiff base have also been explored against pathogenic bacteria.

Copyright (C2021 Bhaskar Biswas, et al.

DOI: https://doi.org/10.37256/amtt.212021719

This is an open-access article distributed under a CC BY license

(Creative Commons Attribution 4.0 International License)

https://creativecommons.org/licenses/by/4.0/ 


\section{Experimental}

\subsection{Preparation of the Schiff base}

\subsubsection{Chemicals, solvents and starting materials}

Pure $o$-anisidine (Sigma Aldrich, USA) and o-vanillin (Sigma Aldrich, USA) were purchased from the commercial outlets. All the chemicals and reagents of analytical grade were used as received.

\subsubsection{Synthesis of the Schiff base}

The Schiff base compound was designed and prepared according to the reported procedure [20]. The Schiff base was synthesized by refluxing $o$-anisidine $(1 \mathrm{mmol}, 0.123 \mathrm{~g}$ ) with o-vanillin $(1 \mathrm{mmol}, 0.152 \mathrm{~g})$ in $20 \mathrm{ml}$ ethanol for $6 \mathrm{~h}$. Thereafter, the reddish coloured solution was filtered and dried. Then, the Schiff base was stored over $\mathrm{CaCl}_{2}$ for use. Yield: $0.219 \mathrm{~g}(\sim 85.2 \%)$. Anal. Calc. for $\mathrm{C}_{15} \mathrm{H}_{15} \mathrm{NO}_{3}(\mathrm{~L})$ : C, 70.02; H, 5.88; N, 5.44; Found: C, 70.09; H, 5.80; N, 5.93. Infrared (IR) $\left(\mathrm{KBr}, \mathrm{cm}^{-1}\right.$; Figure S1): $3435\left(\mathrm{n}_{\mathrm{OH}}\right), 1617\left(\mathrm{n}_{\mathrm{C}=\mathrm{N}}\right)$; UV-Vis $\left(\lambda_{\max }, \mathrm{nm}\right.$; Figure S2): 279, 341, 463; ${ }^{1} \mathrm{H}$ NMR $(\delta$ ppm, $400 \mathrm{Mz}, \mathrm{CDCl}_{3}$; Figure S3) $\delta=14.46(\mathrm{~s}, 1 \mathrm{H}), 8.70(\mathrm{~s}, 1 \mathrm{H}), 7.26-6.82(\mathrm{Ar}-\mathrm{H}, 7 \mathrm{H}), 5.94(\mathrm{~s}, 1 \mathrm{H}), 3.93,3.89(\mathrm{~d}, 6 \mathrm{H})$ ppm. ${ }^{13} \mathrm{C}$ NMR $\left(400 \mathrm{MHz}, \mathrm{CDCl}_{3}\right.$; Figure S4): $161.43(\mathrm{HC}=\mathrm{N}) ; 153.19,152.78\left(\mathrm{Ar}_{-} \mathrm{OCH}_{3}\right) ; 136.42(\mathrm{Ar}-\mathrm{N}=\mathrm{C}) ; 148.89$ (Ar-OH); 128.15, 123.60, 121.03, 119.34, 119.25, 118.09, 114.40, 112.07 (Ar-C); 56.24, 55.97 (-OCH $)$. ESI-MS (m/z; Figure S5) 258.2663 (Calc. 258.28).

\subsection{Physical measurements}

IR spectrum of the Schiff base was recorded with a SHIMADZU Fourier-transform infrared spectroscopy (FTIR)8400S spectrophotometer with $\mathrm{KBr}$ pellet. The Nuclear magnetic resonance (NMR) spectra of L were obtained on a Bruker Advance $400 \mathrm{MHz}$ spectrometer in $\mathrm{CDCl}_{3}$. Steady-state absorption data was measured using a JASCO V-730 UV-Vis spectrophotometer. ESI mass spectrum of L was measured with a Q-tof-micro quadruple mass spectrometer. Elemental analysis was carried out on a Perkin Elmer 2400 CHN microanalyser.

\subsection{Crystal structure determination and refinement}

The Single crystal X-ray diffraction data of the Schiff base were collected on a Rigaku XtaLABmini diffractometer with Mercury 375R $(2 \times 2$ bin mode $)$ CCD detector. The diffraction data were recorded with graphite monochromated Mo-K $\alpha$ radiation $(\lambda=0.71073 \AA$ ) at 100.0 (2) K using $\omega$ scans. The data were reduced using CrysAlisPro 1.171.38.46 [21] and the space group determination by Olex2. The structural refinement parameter were resolved by dual space method using SHELXT-2015 [22] and refined with full-matrix least-squares procedures employing the SHELXL-2015 [23] through OLEX2 suite [24].

\subsection{Hirshfeld surface calculations of the Schiff base}

Crystal Explorer 17.5 [25] program package was employed to generate Hirshfeld surfaces [26] and 2D fingerprint plots [27] of L using its single-crystal X-ray diffraction data. It has already been established that Hirshfeld Surface analysis is a very important tool to study and locate intermolecular interactions within a crystal packing. The function $\mathrm{d}_{\text {norm }}$ is a ratio of the distances of any surface point to the nearest interior $\left(\mathrm{d}_{\mathrm{i}}\right)$ and exterior $\left(\mathrm{d}_{\mathrm{e}}\right)$ atom and the van der Waals radii of the atoms [28]. The normalized contact distance $\left(\mathrm{d}_{\text {norm }}\right)$ could be expressed as

$$
d_{\text {norm }}=\frac{d_{i}-r_{i}^{v d W}}{r_{i}^{v d W}}+\frac{d_{e}-r_{e}^{v d W}}{r_{e}^{v d W}}
$$

Where, $r_{e}^{v d W}$ and $r_{i}^{v d W}$ denote the corresponding van der Waals radii of atoms. The details of negative value of $d_{\text {norm}}$, the red colour, and the blue colour in Hirshfeld surfaces are described elsewhere [27, 28]. 


\subsection{Antibacterial activity of the Schiff base}

Different pathogenic bacteria were used to examine the antibacterial properties of the Schiff base. Three grampositive strains (Listeria monocytogenes (MTCC 657), Bacillus cereus DGA14 (MN809373) and Staphylococcus aureus S5 (MW073410)) and three gram-negative strains (Salmonella typhimurium MTCC 660, Pseudomonas aeruginosa S3 (MW073400) and Shigella flexneri MTCC 1457) were taken for antimicrobial assay. The strains L. monocytogenes, S. typhimurium and S. flexneri were procured from Institute of Microbial Technology (IMTECH), Chandigarh and the other three strains were isolated in the Plant Biotechnology Laboratory, Department of Biotechnology, University of North Bengal, India. The accession numbers of the partial 16S Ribosomal ribonucleic acid (rRNA) gene sequences of the isolated strains that were deposited to GenBank are mentioned in parentheses initially. All the strains were grown at $37^{\circ} \mathrm{C}$ for $24 \mathrm{~h}$ in nutrient agar media and then stored at $4^{\circ} \mathrm{C}$ for further use.

In vitro bactericidal activity of the Schiff base compound was tested using the agar well diffusion assay [29]. The pathogenic bacteria were cultured in Nutrient broth followed by incubation for $24 \mathrm{~h}$ at $37^{\circ} \mathrm{C}$. Approximately $20 \mathrm{ml}$ of sterile molten and cooled Nutrient agar was poured in sterilized Petri dishes. Thereafter, $100 \mu \mathrm{L}\left(10^{6} \mathrm{CFU} / \mathrm{mL}\right) \mathrm{of}$ the respective strains were inoculated on nutrient agar plates by spread plate method and agar wells of 9 mm diameter were prepared with a sterilized stainless steel cork borer. About $50 \mu 1$ of different concentrations $(1 \mathrm{mM}, 2.5 \mathrm{mM}, 5 \mathrm{mM}$ and $10 \mathrm{mM}$ ) of the compound dissolved in dimethylsulfoxide (DMSO) were added into the wells. DMSO without addition of the compound was also kept in one well to understand the effect of solvent for antimicrobial activity. The plates were incubated at $37^{\circ} \mathrm{C}$ and after $24 \mathrm{~h}$ of incubation, the zones of inhibition developed were measured and noted down [30].

\subsubsection{Determination of minimum inhibitory concentration (MIC) and minimum bactericidal concentration (MBC) of the Schiff base}

For the estimation of MIC, a stock solution of $50 \mathrm{mM}$ was prepared in DMSO from where $4.5 \mathrm{ml}$ was mixed with $10 \mathrm{ml}$ of nutrient broth $(450 \mu \mathrm{l} / \mathrm{ml})$ to obtain a final concentration of $22.5 \mathrm{mM}$. From this, several dilutions were made up to $1 \mathrm{mM}$ concentration. Then, $50 \mu \mathrm{l}$ of fresh microbial inoculums was added to $5 \mathrm{ml}$ of each dilution in $15 \mathrm{ml}$ glass tube making the final concentrations of $0.9 \mathrm{mM}, 1.1 \mathrm{mM}, 1.3 \mathrm{mM}$ up to $22.3 \mathrm{mM}$ and allowed the set up at $37^{\circ} \mathrm{C}$ for $24 \mathrm{~h}$ to grow. Negative and positive control contained $5.05 \mathrm{ml}$ of inoculated broth and compound respectively. The visual turbidity was examined before and after incubation following a reported procedure during $24 \mathrm{~h}$ of incubation [31]. Further, MBC which presents the lowest concentration of $\mathrm{L}$ that prevents the growth of bacterial colony on the solid media was determined by subculturing the above (MIC) dilutions [31].

\section{Results and discussion}

\subsection{Synthesis and formulation of the Schiff base (L)}

The reddish coloured Schiff base ligand, $\mathrm{L}$ is synthesized by refluxing $o$-anisidine with o-vanillin in ethanol medium. Single crystals of the Schiff base were grown in the saturated solution of Schiff base in ethanol medium using slow evaporation technique (Figure 1). The Schiff base exhibits good solubility in methanol, ethanol, and dimethylsulphoxide.

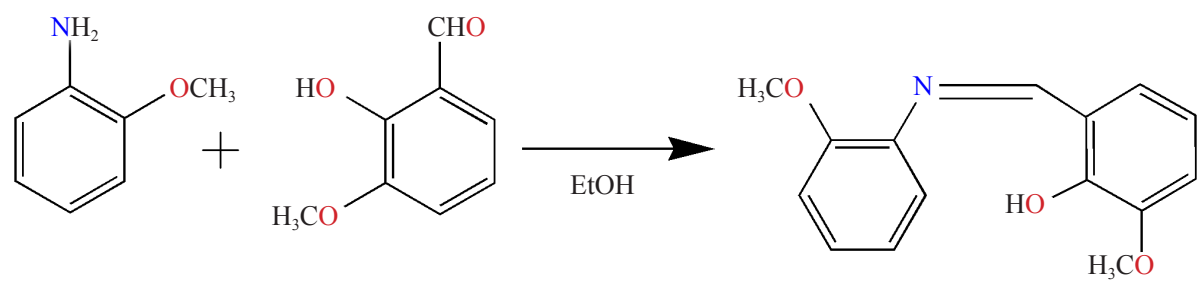

Figure 1. Synthetic route for the formation of the Schiff base 


\subsection{Description of crystal structure}

The crystal structure analysis of the Schiff base reveals that the compound crystallizes in orthorhombic system with $P$ ca2 ${ }_{1}$ space group. An ellipsoidal plot of the Schiff base is shown in Figure 2. The X-ray refinement parameter of the Schiff base is given in Table 1.

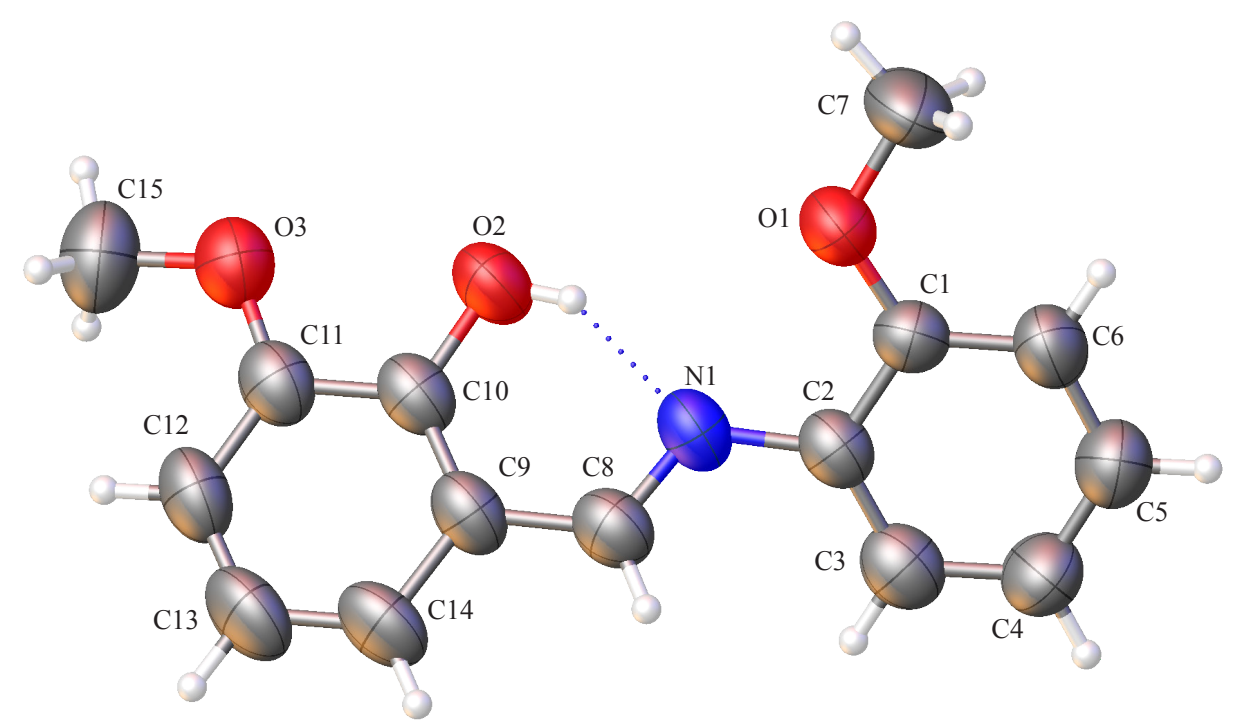

Figure 2. Molecular structure of the Schiff base complex with 30\% ellipsoid probability

Table 1. Crystallographic data and structure refinement parameters for $\mathrm{L}$

\begin{tabular}{|c|c|}
\hline Parameters & $\mathrm{L}$ \\
\hline Empirical formula & $\mathrm{C}_{15} \mathrm{H}_{15} \mathrm{NO}_{3}$ \\
\hline Formula weight & 257.28 \\
\hline Temperature (K) & 296 \\
\hline Crystal system & Orthorhombic \\
\hline Space group & $P \mathrm{ca} 2_{1}$ \\
\hline $\mathrm{a}(\AA)$ & $23.723(3)$ \\
\hline $\mathrm{b}(\AA)$ & $7.7146(9)$ \\
\hline c $(\AA)$ & $7.3608(5)$ \\
\hline Volume $\left(\AA^{3}\right)$ & $1347.1(2)$ \\
\hline $\mathrm{Z}$ & 4 \\
\hline$\rho\left(\mathrm{gcm}^{-3}\right)$ & 1.269 \\
\hline$\mu\left(\mathrm{mm}^{-1}\right)$ & 0.089 \\
\hline $\mathrm{F}(000)$ & 544 \\
\hline $\mathrm{R}_{\text {int }}$ & 0.040 \\
\hline$\theta$ ranges $\left(^{\circ}\right)$ & $2.6-32.7$ \\
\hline Number of unique reflections & 4469 \\
\hline Total number of reflections & 10018 \\
\hline Final $\mathrm{R}$ indices & $0.0601,0.2106$ \\
\hline Largest peak and hole $\left(\mathrm{e} \AA^{-3}\right)$ & $0.17,-0.16$ \\
\hline
\end{tabular}


Table 2. Bond angles and bond distances value of 1

\begin{tabular}{|c|c|c|c|}
\hline \multicolumn{4}{|c|}{ Bond distances $(\AA)$} \\
\hline $\mathrm{O} 1-\mathrm{C} 1$ & $1.356(5)$ & $\mathrm{O} 1-\mathrm{C} 7$ & $1.423(7)$ \\
\hline $\mathrm{O} 2-\mathrm{C} 10$ & $1.358(6)$ & O3-C11 & $1.355(6)$ \\
\hline O3-C15 & $1.422(7)$ & N1-C8 & $1.290(6)$ \\
\hline $\mathrm{N} 1-\mathrm{C} 2$ & $1.424(6)$ & $\mathrm{C} 1-\mathrm{C} 2$ & $1.403(6)$ \\
\hline $\mathrm{C} 1-\mathrm{C} 6$ & $1.386(6)$ & $\mathrm{C} 2-\mathrm{C} 3$ & $1.385(6)$ \\
\hline $\mathrm{C} 3-\mathrm{C} 4$ & $1.387(7)$ & $\mathrm{C} 4-\mathrm{C} 5$ & $1.366(8)$ \\
\hline $\mathrm{C} 5-\mathrm{C} 6$ & $1.368(7)$ & C8-C9 & $1.455(7)$ \\
\hline C9-C10 & $1.388(6)$ & C9-C14 & $1.417(6)$ \\
\hline $\mathrm{C} 10-\mathrm{C} 11$ & $1.414(7)$ & $\mathrm{C} 11-\mathrm{C} 12$ & $1.387(7)$ \\
\hline $\mathrm{C} 12-\mathrm{C} 13$ & $1.383(8)$ & $\mathrm{C} 13-\mathrm{C} 14$ & $1.366(8)$ \\
\hline \multicolumn{4}{|c|}{ Bond angles $\left({ }^{\circ}\right)$} \\
\hline $\mathrm{C} 1-\mathrm{O} 1-\mathrm{C} 7$ & $117.8(4)$ & $\mathrm{C} 1-\mathrm{C} 2-\mathrm{C} 3$ & $119.4(4)$ \\
\hline $\mathrm{C} 11-\mathrm{O} 3-\mathrm{C} 15$ & 116.6(4) & $\mathrm{C} 2-\mathrm{C} 3-\mathrm{C} 4$ & $120.3(4)$ \\
\hline $\mathrm{C} 10-\mathrm{O} 2-\mathrm{H} 2$ & 109.00 & $\mathrm{C} 3-\mathrm{C} 4-\mathrm{C} 5$ & $119.4(4)$ \\
\hline C2-N1-C8 & $120.0(4)$ & C4-C5-C6 & $121.5(5)$ \\
\hline $\mathrm{O} 1-\mathrm{C} 1-\mathrm{C} 2$ & $115.3(4)$ & C1-C6-C5 & $120.1(5)$ \\
\hline $\mathrm{O} 1-\mathrm{C} 1-\mathrm{C} 6$ & $125.4(4)$ & C8-C9-C10 & $121.2(4)$ \\
\hline $\mathrm{O} 2-\mathrm{C} 10-\mathrm{C} 9$ & 123.1(4) & C8-C9-C14 & $119.0(4)$ \\
\hline $\mathrm{O} 2-\mathrm{C} 10-\mathrm{C} 11$ & $116.6(4)$ & C10-C9-C14 & $119.7(4)$ \\
\hline $\mathrm{O} 3-\mathrm{C} 11-\mathrm{C} 12$ & $125.6(4)$ & C9-C10-C11 & $120.3(4)$ \\
\hline $\mathrm{O} 3-\mathrm{C} 11-\mathrm{C} 10$ & $116.0(4)$ & $\mathrm{C} 10-\mathrm{C} 11-\mathrm{C} 12$ & $118.4(5)$ \\
\hline N1-C2-C1 & $116.9(4)$ & $\mathrm{C} 11-\mathrm{C} 12-\mathrm{C} 13$ & $121.2(5)$ \\
\hline N1-C2-C3 & $123.5(4)$ & C12-C13-C14 & $121.0(5)$ \\
\hline N1-C8-C9 & $120.4(5)$ & C9-C14-C13 & $119.4(5)$ \\
\hline $\mathrm{C} 2-\mathrm{C} 1-\mathrm{C} 6$ & 119.3(4) & & \\
\hline
\end{tabular}

The bond distances and bond angles of the Schiff base are specified in Table 2. It is observed that the Schiff base consists of three main functional sites-phenoxo, azomethine and methoxy groups. More interestingly, all the four donor sites (two methoxy-O, one azo methane-N and one phenoxo-O) appear in the same side to present the $Z$-stereomer of the Schiff base in the crystalline phase. It is also observed that the phenoxo-H couples strongly with the azomethine-N with strong intramolecular H-bonding and lock the side in a plane.

Investigation on self-assembly of the Schiff base, it is observed that methoxy-O makes intermolecular H-bonded network with the $\mathrm{H}$ attached to the carbon atom of phenyl and grows in a 3D architecture in $a c$ plane (Figute 3, Table $\mathrm{S} 1)$. The intermolecular H-bonded interactions are of moderate strength $(\mathrm{O} 3 \cdots \mathrm{H} 12,2.64 \AA)$ and assembled in a definite fashion.

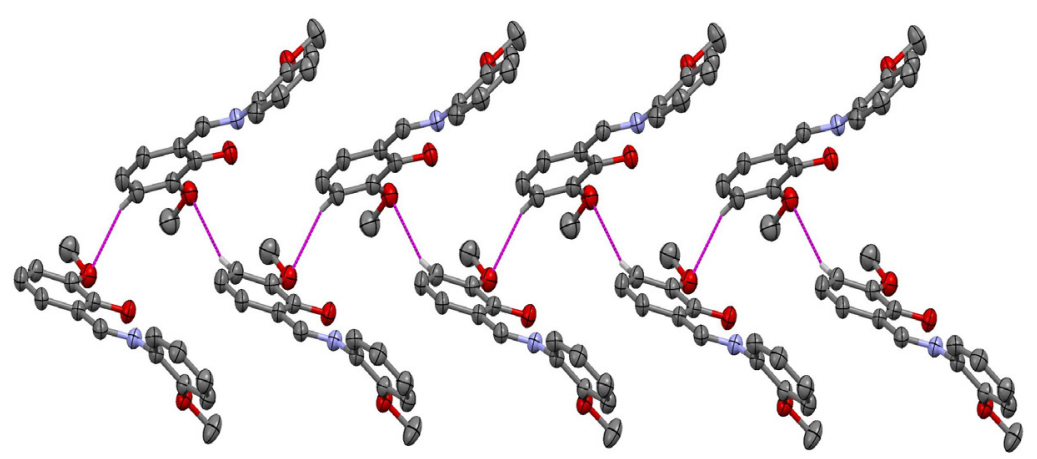

Figure 3. $\mathrm{O} \cdots \mathrm{H}$ interactions mediated supramolecular architecture of the Schiff base 


\subsection{Hirshfeld analysis of the Schiff base}

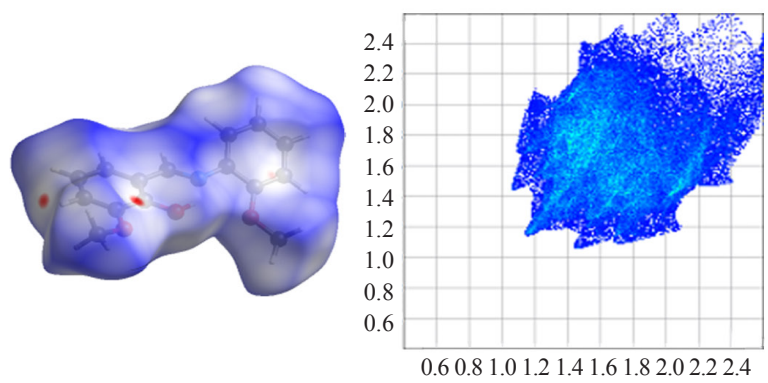

All-in All-out (100\%)

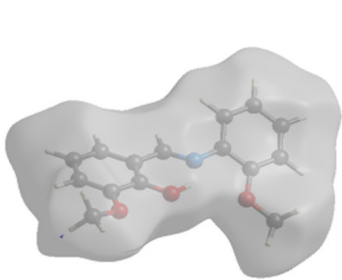

All-in N-out (1.0\%)

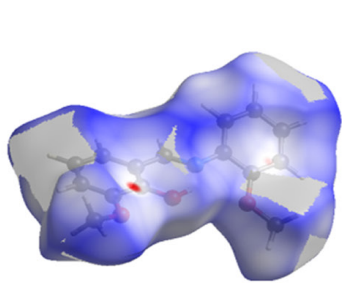

All-in H-out (77.2\%)
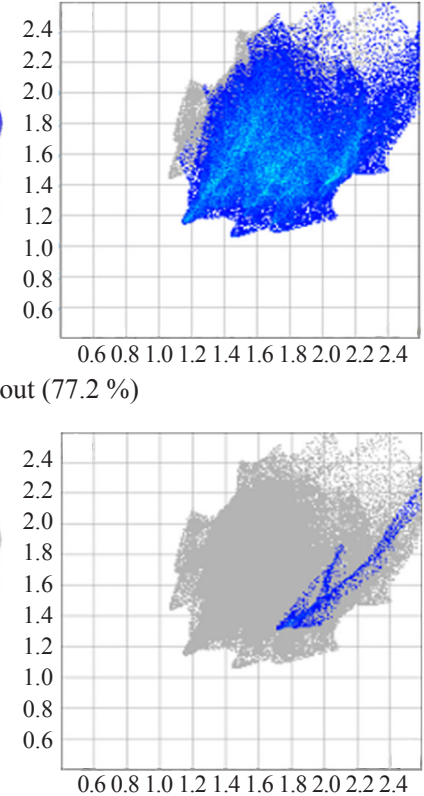

$\mathrm{N}$-in All-out (1.6\%)
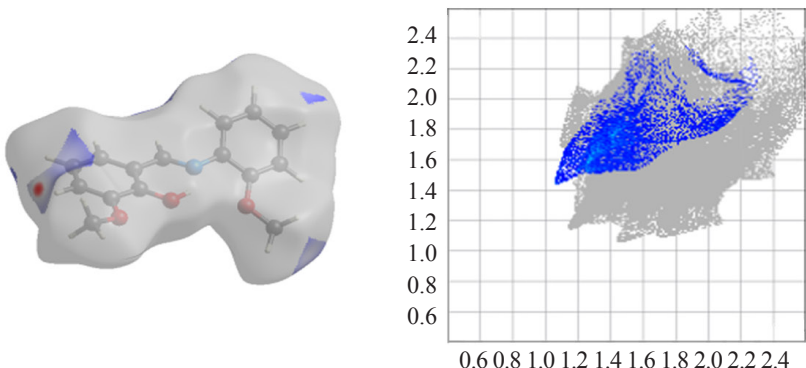

All-in O-out ( $8.5 \%)$
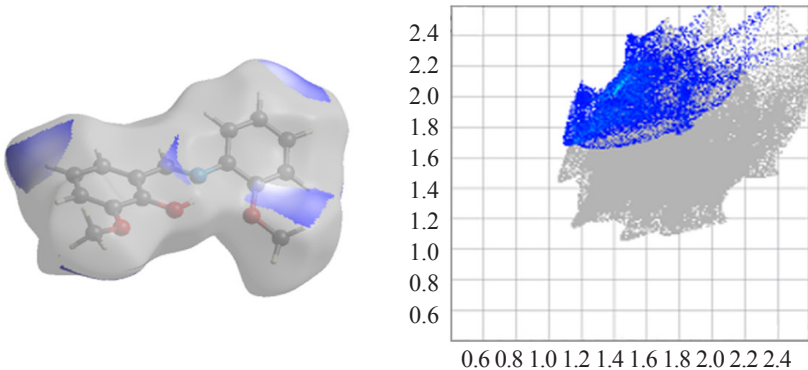

All-in C-out (13.3\%)
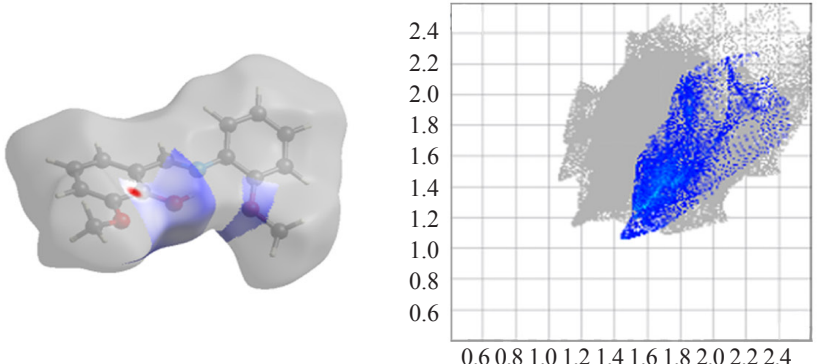

O-in All-out (10.1\%)
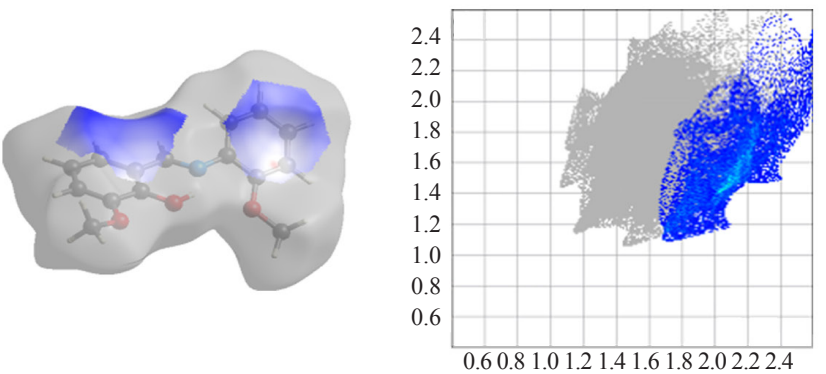

C-in All-out (19.3\%)
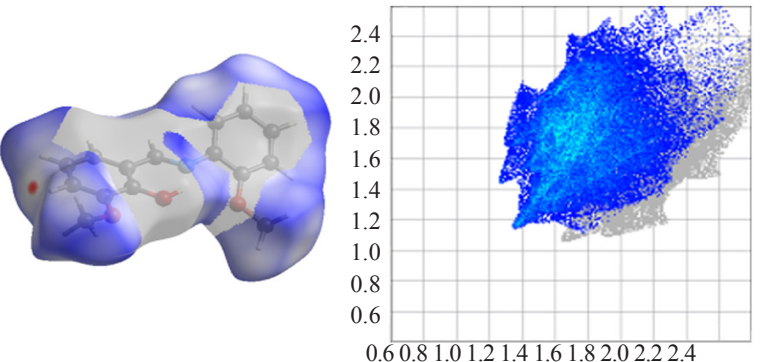

$\mathrm{H}$-in All-out (69.1\%)

Figure 4. Fingerprint plot of the Schiff base 
Hirshfeld surface analysis of the Schiff base was calculated over a definite $\mathrm{d}_{\text {norm }}$ with Crystal Explorer software. The surface volume and surface area were calculated as $330.13 \AA^{3}$ and $312.88 \AA^{2}$ respectively. The red highlighted area displays the $\mathrm{d}_{\text {norm }}$ area and non-covalent interactions of the Schiff base with the neighbour in the crystal. The percentage share of each element in close interaction with others is given in Table S2. In the $\mathrm{d}_{\text {norm }}$ plot, the red area displays the moderate intermolecular C-H $\cdots \mathrm{O}$ interactions as displayed in Fingerprint plots (Figure 4). Table S2 provides quantitative information of the H-bonded interactions by each pair of elements.

\subsection{Solution phase behaviour of the Schiff base}

The solution phase behaviour is very important for a molecule to view its intricate photophysical properties as well as molecular integrity. The solution phase properties were studied with different spectroscopic methods especially UVVis, ESI-Ms and spectrofluorimetry. The UV-Vis spectrum of the Schiff base was recorded in acetonitrile (MeCN) at room temperature. The Schiff base displayed electronic bands of high absorbance at 278, $340 \mathrm{~nm}$ and a broad band with low absorbance at $460 \mathrm{~nm}$ (Figure S1). The electronic bands at 278 and $340 \mathrm{~nm}$ for the Schiff base may be assigned as $\pi \rightarrow \pi^{*} / \mathrm{n} \rightarrow \pi^{*}$ electronic transitions of ligand origin. The appearance of optical band at $460 \mathrm{~nm}$ is attributed to the ligand centric charge transition [20].

ESI-Ms spectrum of the Schiff base was also measured in $\mathrm{MeCN}$ and shown in Figure S5. The molecular ion peak for the Schiff base was appeared at m/z 258.6663 which also ensured the molecular integrity of the Schiff base in solution phase. The experimental $\mathrm{m} / \mathrm{z}$ value also agrees well with the calculated $\mathrm{m} / \mathrm{z}$ value of the Schiff base. The solvatochromism property of the Schiff base was further examined in different solvents like tetrahydrofuran (THF), dichoromethane (DCM), propan-2-ol and acetonitrile at room temperature. It is observed that the colour of the solution of the Schiff base remains yellowish red to red in different solvent. It is further noted that upon moving from non-polar to polar solvent, the compound exhibits a bathochromic shift of $\sim 5 \mathrm{~nm}$. Figure S6 represents the absorption profile of the Schiff base in different solvent media. Probably, the excited states of the Schiff base get more stabilized with the increase of polarity of the solvent.

The fluorescence behaviour of the Schiff base was examined in MeCN and presented in Figure S7. The Schiff base exhibits moderate fluorescence behaviour which may be explained by considering the intramolecular coupling of phenoxo-H with imine-N. Phenoxo-H in locked condition in general exhibit poor fluorescence properties [20].

\subsection{Antibacterial activity}

The bactericidal activity of the Schiff base compound was studied by Agar well diffusion method and the compound exhibited a noticeable zone of inhibition against different pathogenic bacteria while no such antibacterial activity was shown by DMSO. The organic molecules as the basic structural unit have been studied as potential antibiotics [32] and recently investigated by researchers in an attempt to develop antibacterial agents capable of overcoming bacterial resistance. In this study, our synthesized compound showed its antimicrobial effectiveness towards both the groups of bacteria with the most susceptible being gram-negative bacteria $S$. flexneri (Figure S8).

The estimation of MIC was done both qualitatively and quantitatively. The MIC and MBC values of the Schiff base against the pathogens are summarized in Table 3.

Table 3. MIC and MBC value of compound against the test pathogens

\begin{tabular}{cccc}
\hline & Pathogens & $\begin{array}{c}\text { MIC } \\
(\mathrm{mM})\end{array}$ & $\begin{array}{c}\text { MBC } \\
(\mathrm{mM})\end{array}$ \\
\hline \multirow{2}{*}{ Gram $+v e$} & Bacillus cereus & 2.1 & 8.7 \\
& Listeria monocytogenes & 1.7 & 2.9 \\
Gram $-\mathrm{ve}$ & Staphylococcus aureus & 4.5 & 15.1 \\
& Pseudomonas aeruginosa & 1.5 & 4.5 \\
& Salmonella typhimurium & 2.1 & 6.5 \\
\hline
\end{tabular}


The Schiff base showed the highest MIC value of $4.5 \mathrm{mM}$ for $S$. aureus and the lowest value of $1.3 \mathrm{mM}$ for $S$. flexneri. The bactericidal activity of the compound ranged in the order $S$. flexneri $>$ L. monocytogenes $>$ P. aeruginosa $>$ S. typhimurium $>$ B. cereus $>S$. aureus with lowest MBC of $2.1 \mathrm{mM}$ for $S$. flexneri and highest MBC of $15.1 \mathrm{mM}$ for $S$. aureus (Figure 5).

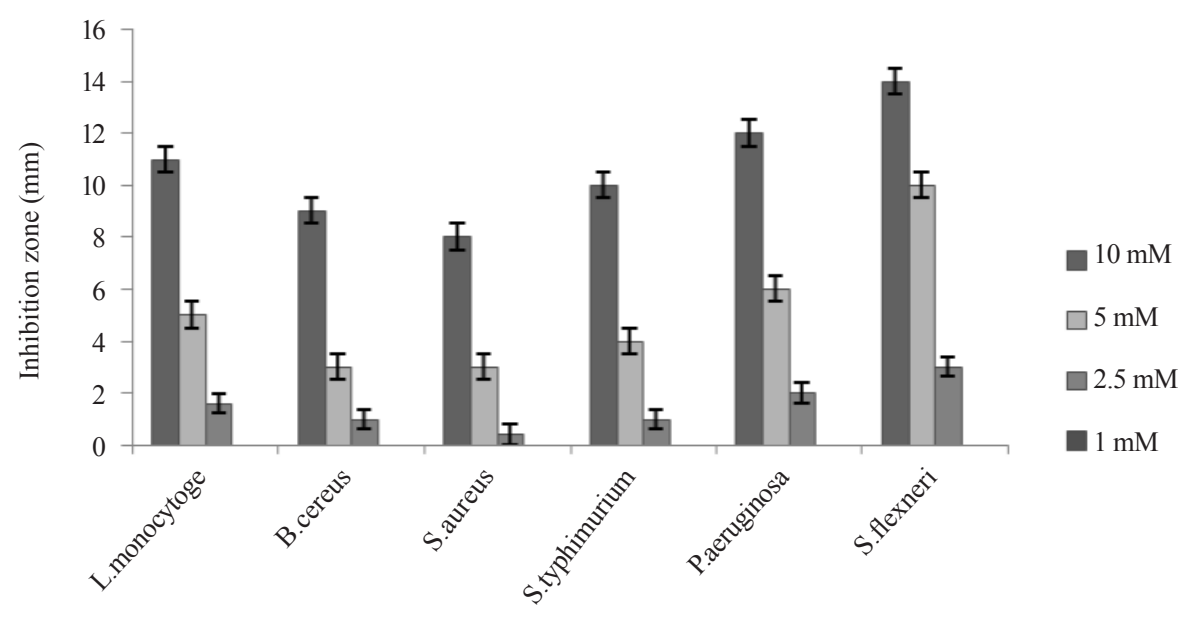

Figure 5. Bar diagram of antimicrobial activity of the Schiff base against some pathogenic bacteria at different concentrations. Inhibition zone was calculated as: diameter of inhibition zone-diameter of well $(9 \mathrm{~mm})$.

Data are represented as triplicate of mean \pm SD. No zone was observed in $1 \mathrm{mM}$ concentration of compound against all the pathogens

From the combined result of agar well diffusion method and quantitative estimation of antibacterial activity, it was observed that the Schiff base was highly effective against $S$. flexneri showing the lowest MIC and MBC values whereas the least effectivity was found against $S$. aureus giving the highest MIC and MBC values (Figure 5). It was observed that gram-negative bacteria were more susceptible towards this Schiff base than the gram-positive bacteria. Gram-negative bacteria are supposed to consider harder to treat with antimicrobial agents because of their outer membrane serves as a permeability barrier. Therefore, exhibits higher levels of antibacterial resistance and consequently can exclude the antibiotics from penetrating the cell [33]. However, vanilin functionalized derivatives have been found to show its antibacterial activity against gram-negative bacteria like $P$. aeruginosa and E. coli with the mechanism being still unclear [34]. Similar observation was made for a novel N-acyl substituted indole linked benzimidazoles which showed a broad-spectrum antibacterial activity against E. fecalis, P. aeruginosa, E. coli and $S$. aureus [35]. Some mechanistic studies point to the membrane-permeabilizing effect of the indole derivative compounds against bacterial pathogens $[36,37]$. A transcriptome data of $P$. putida upon indole treatment show that exogenous indole can cause a reduction in adenosine triphosphate (ATP) production by membrane perturbation [38]. However, elucidation of the respective roles of membrane permeabilization and depolarization is of utmost importance for understanding the mechanisms of action of such antimicrobial agents.

\section{Conclusions}

An o-vanillin functionalized Schiff base was synthesized and crystallographically characterized. The structural formulation and solution phase behaviour were studied with different conventional spectroscopic methods. The X-ray crystal structure shows that the Schiff base crystallizes in orthorhombic system with $P$ ca $2_{1}$ space group. The Schiff base exhibits moderate fluorescence property in MeCN. The Schiff base shows highest bactericidal activity against $S$. flexneri in a concentration-dependent manner. The molecules will certainly enrich the molecular library of the Schiff base with good bactericidal activity. 


\section{Supplementary data}

Supplementary crystallographic data are available free of charge from The Director, CCDC, 12 Union Road, Cambridge, CB2 1EZ, UK (fax: +44-1223-336033; E-mail: deposit@ccdc.cam.ac.uk or www: http://www.ccdc.cam. ac.uk) upon request, quoting deposition number CCDC 2050514 for the Schiff base ligand. Experimental information such FT-IR, UV-Vis, ${ }^{1} \mathrm{H} \&{ }^{13} \mathrm{C}$ NMR, ESI mass spectrum, inhibition of bacterial growth, Fluoresecence spectrum, Hirshfeld surface plot elemental contribution parameter etc are given here.

\section{References}

[1] Zoubi WA, Ko YG. Schiff base complexes and their versatile applications as catalysts in oxidation of organic compounds: part I. Applied Organometallic Chemistry. 2017; 31: e3574. Available from: https://doi.org/10.1002/ aoc.3574.

[2] Chowdhury B, Karar M, Paul S, Joshi M, Choudhury AR, Biswas B. Salen type ligand as a selective and sensitive Nickel(II) ion chemosensor: A combined investigation with experimental and theoretical modelling. Sensors and Actuators B: Chemical. 2018; 276: 560-566.

[3] Weng Q, Yi J, Chen X, Luo D, Wang Y, Sun W, Kang J, Han Z. Controllable synthesis and biological application of schiff bases from D-glucosamine and terephthalaldehyde. ACS Omega. 2020; 5: 24864-24870.

[4] Das S, Nath S, Singh TS, Nitin Chattopadhyay N. Cavity size dependent stoichiometry of probe-cyclodextrin complexation: Experimental and molecular docking demonstration, Journal of Photochemistry and Photobiology. 2020; 388: 112158.

[5] Biswas B, Raghavaiah P, Aliaga-Alcalde N, Chen J-D, Ghosh R. Syntheses, crystal structures and properties of a new family of isostructural and isomorphous compounds of type $[\mathrm{M}(\mathrm{L})(\mathrm{NCS}) 3][\mathrm{M}=\mathrm{La}, \mathrm{Gd}, \mathrm{Tb}$ and $\mathrm{Dy} ; \mathrm{L}=\mathrm{a}$ neutral hexadentate Schiff base]. Polyhedron. 2010; 29: 2716-2721.

[6] Malakzadeh S, Alizadeh N. Spectroscopic study and antioxidant activity of the inclusion complexes of cyclodextrins and amlodipine besylate drug. Journal of Inclusion Phenomena and Macrocyclic Chemistry. 2018; 90: 89-98.

[7] Ghosh P, Roy BG, Jana S, Mukhopadhyaye SK, Banerjee P. Colorimetric and fluorimetric response of Schiff base molecules towards fluoride anion, solution test kit fabrication, logical interpretations and DFT-D3 study. Physical Chemistry Chemical Physics. 2015; 17: 20288-20295.

[8] Mahato S, Meheta N, Muddukrishnaiah K, Joshi M, Ghosh P, Shit M, Choudhury AR, Biswas B. Ligand directed synthesis of a unprecedented tetragonalbipyramidal copper(II) complex and its antibacterial activity and catalytic role in oxidative dimerisation of 2-aminophenol. Applied Organometallic Chemistry. 2020; 34(11): e5935. Available from: DOI: 10.1002/aoc.5935.

[9] Das S, Sahu A, Joshi M, Paul S, Shit M, Choudhury AR, Biswas B. Ligand-centered radical activity by a zincSchiff-base complex towards catechol oxidation. Chemistry Select. 2018; 3: 10774-10781.

[10] Biswas B, Pal A, Krishna GR, Reddy CM, Tuna F, Ghosh R. An antiferromagnetically coupled dimeric Ni(II) complex anion and its counter cationic monomeric Ni(II) complex, and some other mononuclear transition metal compounds using some neutral ligands. Polyhedron. 2011; 30: 2032-2037.

[11] Chemchem M, Yahaya I, Aydiner B, Doluca O, Seferoglu N, Seferoglu Z. Substituent dependent selectivity of fluorescent chemosensors derived from coumarin for biologically relevant DNA structures and anions. Sensors and Actuators B: Chemical. 2020; 305: 127316.

[12] Aydiner B, Sahin O, Cakmaz D, Kaplan G, Kaya K, Ozdemir UO, Seferoglu N, Seferoglu Z. A highly sensitive and selective fluorescent turn-on chemosensor bearing a 7-diethylaminocoumarin moiety for the detection of cyanide in organic and aqueous solutions. New Journal of Chemistry. 2020; 44: 19155-19165.

[13] Dutta S, Bhunia P, Mayans J, Drew MGB, Ghosh A. Roles of basicity and steric crowding of anionic coligands in catechol oxidase-like activity of $\mathrm{Cu}(\mathrm{II})-\mathrm{Mn}(\mathrm{II})$ complexes. Dalton Transactions. 2020; 49: 11268-11281.

[14] Maity S, Bhunia P, Ichihashi K, Ishida T, Ghosh A. SMM behaviour of heterometallic dinuclear $\mathrm{Cu}^{\mathrm{II}} \mathrm{Ln}^{\mathrm{III}}(\mathrm{Ln}=\mathrm{Tb}$ and Dy) complexes derived from $\mathrm{N}_{2} \mathrm{O}_{3}$ donor unsymmetrical ligands. New Journal of Chemistry. 2020; 44: 61976205.

[15] Sarkar A, Chakraborty A, Chakraborty T, Purkait S, Samanta D, Maity S, Das D. A Chemodosimetric approach for fluorimetric detection of $\mathrm{Hg}^{2+}$ ions by trinuclear $\mathrm{Zn}(\mathrm{II}) / \mathrm{Cd}$ (II) Schiff base complex: First case of intermediate trapping in a chemodosimetric approach. Inorganic compound. 2020; 59(13): 9014-9028.

[16] Chowdhury T, Dasgupta S, Khatua S, Acharya K, Das D. Executing a series of Zinc(II) complexes of homologous 
Schiff base ligands for a comparative analysis on hydrolytic, Anti-oxidant and Anti-bacterial activities. ACS Applied Bio Materials Forums. 2020; 3(7): 4348-4357.

[17] Basak T, Frontera A, Chattopadhyay S. Existence of stronger C-H $\cdots \pi$ (chelate ring) interaction compared to C- H. $\cdot \pi$ (arene) interactions in the supramolecular assembly of dinuclear iron(III) Schiff base complexes: A theoretical insight. Inorganica Chimica Acta. 2020; 120081. Available from: DOI: 10.1016/j.ica.2020.120081.

[18] Dey D, Pal S, Bag PP, Saha S, Chandraleka S, Dhanasekaran D, Kole N, Biswas B. Copper(II) complexes with a (N, O)-donor Schiff base ligand: Syntheses, crystal structure, DNA interaction study and molecular docking. Journal of the Indian Chemical Society. 2015; 92: 191-202.

[19] Dey D, Kaur G, Patra M, Choudhury AR, Kole N, Biswas B. A perfectly linear trinuclear zinc-Schiff base complex: Synthesis, luminescence property and photocatalytic activity of zinc oxide nanoparticle. Inorganica Chimica Acta. 2014; 421: 335-341.

[20] Mudi PK, Bandopadhyay N, Joshi M, Shit M, Paul S, Choudhury AR, Biswas B. Schiff base triggering synthesis of copper(II) complex and its catalytic fate towards mimics of phenoxazinone synthase activity. Inorganica Chimica Acta. 2020; 505: 119468. Available from: https://doi.org/10.1016/j.ica.2020.119468.

[21] CrysAlisPro 1.171.39.35c. Rigaku Oxford Diffraction, Rigaku Corporation: Tokyo, Japan. 2017.

[22] Sheldrick GM. SHELXT-Integrated space-group and crystal-structure determination Acta. Acta Crystallographica. 2015; A71: 3-8.

[23] Sheldrick GM. Crystal structure refinement with SHELXL. Acta Crystallographica. 2015; C71: 3-8.

[24] Dolomanov OV, Bourhis LJ, Gildea RJ, Howard JAK, Puschmann H. OLEX2: A complete structure solution, refinement and analysis program. Journal of Applied Crystallography. 2009; 42: 339-341.

[25] Turner MJ, McKinnon JJ, Wolff SK, Grimwood DJ, Spackman PR, Jayatilaka D, Spackman MA. Crystal Explorer17. Crystal Explorer. University of Western Australia. 2017. Available from: http://hirshfeldsurface.net17.

[26] Spackman MA, Jayatilaka D. Hirshfeld surface analysis. CrystEngCom. 2009; 11: 19-32.

[27] Seth SK, Lee VS, Yana J, Zain SM, Cunha AC, Ferreira VF, Jordao AK, de Souza MCBV, Wardell SMSV, Wardellf JL, Tiekink ERT. Crystallographic and computational study of 1-(arylamino)-1,2,3-triazole-4-carbohydrazides. CrysEngComm. 2015; 17: 2255-2266.

[28] Spackman MA, McKinnon JJ. Fingerprinting intermolecular interactions in molecular crystals. CrystEngComm. 2002; 4: 378-392.

[29] Perez C. Antibiotic assay by agar-well diffusion method. Advances in Experimental Medicine and Biology. 1990; 15: 113-115.

[30] Monica C. District Laboratory Practice in Tropical Countries. 2nd ed. UK: Cambridge University Press; 2000. p.136-167.

[31] Gunalan S, Sivaraj R, Rajendran V. Green synthesized $\mathrm{ZnO}$ nanoparticles against bacterial and fungal pathogens. Progress in Natural Science: Materials International. 2012; 22(6): 693-700.

[32] Lee JH, Cho HS, Kim Y, Kim JA, Banskota S, Cho MH, Lee J. Indole and 7-benzyloxyindole attenuate the virulence of Staphylococcus aureus. Applied Microbiology and Biotechnology. 2013; 97(10): 4543-4552.

[33] Te Winkel JD, Gray DA, Seistrup KH, Hamoen LW, Strahl H. Analysis of antimicrobial-triggered membrane depolarization using voltage sensitive dyes. Frontiers in Cell and Developmental Biology. 2016; 13(4): 29.

[34] Turner DN, Edwards L, Kornienko A, Frolova LV, Rogelj S. Synergistic action of substituted indole derivatives and clinically used antibiotics against drug-resistant bacteria. Future Microbiology. 2020; 15(8): 579-590.

[35] Wimley WC, Hristova K. Antimicrobial peptides: successes, challenges and unanswered questions. The Journal of Membrane Biology. 2011; 239(1-2): 27-34.

[36] Turner DN, Edwards L, Kornienko A, Frolova LV, Rogelj S. Synergistic action of substituted indole derivatives and clinically used antibiotics against drug-resistant bacteria. Future Microbiology. 2020; 15(8). Available from: https://doi.org/10.2217/fmb-2019-0094.

[37] Chimerel C, Field CM, Piñero-Fernandez S, Keyser UF, Summers DK. Indole prevents Escherichia coli cell division by modulating membrane potential. Biochimica et BiophysicaActa (BBA)-Biomembranes. 2012; 1818(7): 1590-1594.

[38] Kim J, Hong H, Heo A, Park W. Indole toxicity involves the inhibition of adenosine triphosphate production and protein folding in Pseudomonas putida. FEMS Microbiology Letters. 2013; 343(1): 89-99. 